\title{
Application of Scaffolding Instruction to Picture Talk Course for Chinese Beginners
}

\author{
$\mathrm{Li} \mathrm{LI}^{1 *}$ \\ ${ }^{1}$ School of Languages and Cultures, Shanghai University of Political Science and Law \\ lily2211@126.com
}

\begin{abstract}
Speaking is thought of as one of the most indispensable skills for Chinese beginners. Therefore, oral practice plays an essential role in the Chinese language learning. However, the present situation is so far from satisfaction that Picture Talk course is introduced to supplement and enforce oral training. This paper aims at studying Picture Talk course based on scaffolding and analysing how to make full use of various scaffoldings as effective strategies to enhance learner's interest in Chinese learning, improve their speaking ability, facilitate their language competence and offer some suggestions for Chinese language teaching.
\end{abstract}

Keywords: Scaffolding instruction, Oral practice, Internalization, Teaching strategies

\section{INTRODUCTION}

Scaffolding is seen as one of the teaching modes with the support of constructionism. In recent years, Chinese scholars and teachers have conducted meaningful and practical researches on the application of scaffolding in the foreign language teaching, especially in English writing and reading teaching. Though some have studied the application of scaffolding instruction to the Chinese language teaching as a foreign language, few focus on the oral Chinese teaching, not to mention Picture Talk course. The paper aims at studying Picture Talk course with the support of scaffolding instruction and analyzing how to make the best use of a variety of scaffoldings to enhance learner's interest in Chinese learning and help them build up confidence in speaking Chinese so as to improve their speaking ability so as to further facilitate their language competence.

\section{SCAFFOLDING INSTRUCTION}

Scaffolding is based primarily on the work of Lev Vygotsky, a Russian psychologist, educator, philosopher and art critic, who fist put forward the concept of the Zone of Proximal Development (ZPD) which is considered the primary activity space where learning occurs. The most frequent quoted definition is the following:
It is the distance between the actual development level as determined by independent problem solving and the level of potential development as determined through problem solving under adult guidance or collaboration with more capable peers [1].

Evidently, Vygotsky was fond of exploring what individual child /student was capable of achieving with the assistance of knowledgeable partners. In fact, he didn't work out a specific theory using the ZPD as a guiding metaphor to instruct the teaching, but Vygotsky extended the concept of the ZPD to pedagogical activities [2]. His work was so influential that other scholars further put the concept of the ZDP to education and then came up with new theories including "Scaffolding", the most influential one. The term "scaffolding" was first introduced in the works of Wood, Brunner and Ross [3]. The term is used to describe young children's oral language acquisition and later depicted as a process whereby a mental stepping stone allows the student to enter their Zone of Proximal Development [4].

Scaffolding literally refers to a temporary structure on the outside of a building, made of wooden planks and metal poles, used by workmen while building, repairing or cleaning the building. Obviously, according to its definition, it is certain that scaffolding is marked as helpful tools in the construction, which provides the workers with indispensable support so that they can complete their tasks faster and better. Once making it, the workers will remove the scaffolding. 
Later, the term is vividly borrowed and developed by scholars as a metaphor to describe the help provided by a teacher or peer in the learning. The goal of scaffolding is to meet students at their ability level and guide them to grow on step at a time [5]. In the whole process of scaffolding, the teacher helps the student master a task or a skill that he/she is firstly unable to grasp on his/her own. The necessary help is provided for the student when the task or the skill is e beyond his/her ability. What's more important is to allow his/her to complete as much of the task as possible, without more help. Meanwhile, the student is allowed to make a mistake or even an error, but, with teacher feedback and prompting, he/she is able to achieve the goal. Once the student takes responsibility for or master the task, it is the teacher that begins to fade the scaffolding or remove the scaffolding gradually, which gives the student more chances to work independently.

"Scaffolding is actually a bridge used to build upon what students already know arrive at something they do not know. If scaffolding is properly administered, it will act as an enabler, not as a disabler" [6]. Scaffolding is virtually used to indicate how the teachers can facilitate the students' transmission from assisted to independent performance [7]. So what's more important is that various scaffoldings offered to student are able to help them cross the ZDP with the combination of the instruction of the teacher and cooperation between the students and their peers to achieve the final goal.

\section{PICTURE TALK COURSE}

Picture Talk course is mainly taken by Chinese beginners. In the study, Chinese beginners are all adults in Grade One at college or university who show great interests in Chinese culture and also consider Chinese as a main tool in their future career. That is, these Chinese beginners are different from children in their cognition and motivation. Obviously, oral Chinese learning is of great difficulty for the students from other cultures. Few of the students have learned Chinese language before, so the course Picture Talk mainly provides them with more vivid, suitable and supplementary oral training materials to practice. With the help of picture description activity, students' oral production is more coherent, richer in content, and more complex in language forms [8].

As we all know, for little children, images play an important role in the process of acquisition of their mother language. Pictures, serving as the teaching aid, has their particular strong points. It is helpful for students to build up immediately the connection between the meanings and Chinese characters and pinyin because the pictures could remind of them the meaning represented by the sounds and characters. With the assistance of pictures, students could give free rein to their observation and imagination, and thus it is for them to make up logical and meaningful sentences and passages [9].

\section{APPLICTION OF SCAFFOLDING INSTRUCTION TO PICTURE TALK COUSE}

Scaffolding, a teaching strategy, was named for its resemblance it owns to the physical scaffolds applied to the construction sites. In fact, the strategy is involved in teaching new concepts or skills by engaging students collaboratively in the teaching tasks that would be too difficult for them to complete independently. The teacher should provide the students with necessary and meaningful scaffoldings which prompt them to understand what they have just learned and internalize it. In the whole teaching process, the teacher has to convert his/her role from initiator into guide, facilitator, assistant and so on. Therefore, scaffolding can be presented in different forms in the teaching mainly based on the tasks. Five steps are involved in the scaffolding instruction, listed as follows: setting up scaffolding, entering the situation, thinking for themselves, collaborative learning and evaluation. The study just focused on the course of Picture Talk to illustrate how to scaffold the instruction to unfold new concept and task slowly and build various supports into the teaching. In the paper, Unit Four Book One is selected as an example to illustrate scaffolding instruction.

\subsection{Setting up Scaffolding}

On the basis of the theory of the ZPD, the teacher focuses on the teaching task and scaffolds the instruction by reminding the student what they have learned and helping them fit new information. At this step, the teacher should expect students' prior knowledge including their own personal experiences and what they have learned. At first, teacher has to offer clear direction and clarify the learning purpose, which requires that teacher anticipate the difficulty that the students may come across and help them learn why it is important. In the process, students can have a better and deeper understanding of the new task and make sense.

Take Unit Four Book One. This unit mainly talks about Chinese food and tell the story at the canteen. So at the beginning of the class, the teacher must clarify the goal of learning to say some new words and expressions about everyday food and some sentence patterns on the food. The teacher must simplify the new information or task to make it manageable and achievable for Chinese beginner.

\subsection{Entering the Situation}

Good activities should be thought out and designed to arouse their enthusiasm and help them step into the situation unconsciously. Thus, the instructional support or leading scaffolding, such as raising warm-up questions, brainstorming, can be fully used at this step to lead the 
students to the situation which is closed to the real life and arouses their interest. Brainstorming can activate students' prior knowledge build background, which helps them to better understand the new task and have enough prior knowledge to make the connection.

In the teaching of Unit Four, the teacher gives students several pictures where the food the students are familiar with is printed and asks them "What is it?" "Where can they have them?" "What do they usually drink?", and so on. The scaffolding must begin with the students' personal experiences. In this way, some new words are introduced, which can help them to use these to express their ideas in the following group discussion. Naturally, the teacher should give students examples of what is requested of for imitation. In this case, the students are enabled to carry out the task which would have been able to manage on their own. In the real situation, the students' prior knowledge will adapt the new information and their cognitive structure will be enriched in the adaption, which promotes the students to create a new construction on their knowledge. It is an essential process in any language learning, including Chinese language learning, because there exists language fossilization which is a universal phenomenon and a huge barrier in the language learning. Teachers' timely and appropriate guidance can build a bridge to activate their prior knowledge, help students reduce anxiety and build up their confidence in learning Chinese language so as to overcome some difficulties effectively.

\subsection{Thinking for Themselves}

Set aside enough time for the students' thinking. Scaffolding puts great emphasis on the importance of equipping students with tools that allows them to guide their own learning and giving them plenty of space to practice using them. At first, teachers should be patient so the students are allowed to complete something as much as they can individually. Teachers are ready to offer some assistance to individuals if necessary so as to stimulate students' deeper thought and lead them to move forward to the higher level and make a preparation to the next step.

\subsection{Collaborative Learning}

At the step, teacher can employ group discussion or group interaction to fulfil the task. For the Unit Four, the teacher can divide the whole class into several groups, give them several pictures on the food and ask them to talk about these pictures. In the activities, the teacher carefully observes the students' understanding so that as the need arises the teacher can offer timely scaffolding instruction by answering questions and raising heuristic questions. In fact, in the collaboration, scaffolding can be provided not only by the teacher, but also by their peers. In the process, the teacher has to make sure that all the students participate in the activities and share their ideas.
Their cooperation and interaction will highlight their engagement and ownership in the learning process. The students as individuals have strong desires to construct a wider space and make full use of more vivid and colourful materials so that they can move forward to the next level. In the communication with their peers, they will try their utmost to present the best image to others and take the task seriously. Meanwhile, they also can learn from each other and learn to solve problems from different perspectives and develop the habit of thinking critically.

\subsection{Effect Evaluation}

Evaluation on the learning effect is involved in three aspects: self-evaluation, peer-evaluation and teacher's evaluation. Teachers' evaluation plays a central role in the learning process, and has a profound influence on the Chinese beginners, which can't be ignored. In the discussion, presentation or other activities, the teacher has to carefully monitor the students' performance or understanding or even problems, and then make heuristic comments or give them timely feedbacks. Notice that teacher had better make positive comments on the students' job, which serves as an encouraging scaffold so as to help the students build up their confidence and enhance their interest in learning Chinese language so as to increase their cognitive ability.

\section{CONCLUSION}

Scaffolding the teaching requires the use of various strategies, some of which are just listed in the paper. In the process of teaching, some scaffolds are anticipated and pre-planned whereas others are accidental mainly based on the real teaching situations. All the scaffolds employed in the class contribute to making the learning more meaningful and then more prosperous for the students. Under the scaffolding, Picture Talk course centres on the students and provides more materials and opportunities for them to give full play to the initiative so as to develop their Chinese language competence. In the whole teaching process, the teacher serves as an organizer, an instructor, a facilitator, a guide and so on, and provides scaffolding and challenges at each step to prompt the internalization of their knowledge and active construction of what they have learned. In the long run, Chinese beginners gradually develop a good habit of learning to speak Chinese and increase the ability to apply Chinese language into practice.

\section{ACKNOWLEDGMENTS}

This research was financially supported by the fund from China National Institute for SCO International Exchange and Judicial Cooperation (No.20SHJD021) 


\section{REFERENCES}

[1] L S. Vygotsky, Mind in Society: The development of higher psychological processes. Cambridge: Cambridge University Press, 1978

[2] G. Wells, Dialogic Inquiry: Towards a Socialcultural Practice and Theory of Education. Cambridge University Press. 1999

[3] D. Wood, \& J. Brunner, The Role of Tutoring in Problem Solving. Journal of Child Psychology and Psychiatry, 1976, (17)

[4] J. Bruner, Towards a Theory of Instruction. Belknap Press: An Imprint of Harvard University Press. 1974

[5] Lewis, Beth. "Scaffolding Instruction Strategies." ThoughtCo, Aug. 27, 2020,

thoughtco.com/scaffolding-instruction-strategies2081682.

[6] B. Benson, Scaffolding (Coming to Terms). English Journal. 1997, 86 (7), 126-127

[7] L. E. Berk, \& A. Winsler, Scaffolding children's learning: Vygotsky and early childhood education. NAEYC Research and Practice Series, 7 Washington, DC: National Association for Education o Young Children, 1995

[8] Yan Zhai, \& Hongmei Feng, A Study of Chinese Learners' Speaking Fluency Development with Picture Description Activity. TCSOL Studies. 2014, (4), 1-7

[9] Yongshou Ding, Picture Talk. Beijing: Beijing Language and Culture University Press. 2002 